\title{
CYBERNETICS AND SOVIET JURISPRUDENCE
}

\author{
Djangir A. Kertmov*
}

As the science encompassing the most general principles and optimum conditions for controlling different systems, cybernetics can be used in developing public law. This idea has been made more explicit and substantiated in works by Soviet jurists. A Legal Section has been set up in the Scientific Council on Cybernetics of the USSR Academy of Sciences to unite and coordinate theoretical and practical work in the Soviet judicial system with the object of applying cybernetic means and methods in the process of solving problems of law and criminology.

Although all control processes are governed by common rules and have common traits (i.e., obtaining information, coding and processing, storing and transmitting), each process of control proceeds differently, depending on its specificity. This makes necessary a careful study of the specific nature of control, particularly in the sphere of public law, for the purpose of working out the most effective machine language, algorithms, and programming, as well as for developing a logical information machine for solving problems of public law.

I vigorously object to the viewjoint that the application of cybernetics to social processes will entail changes in the class structure of society, that the development of cybernetic techniques will in time lead to man's creative labor being completely replaced by the machine, and that in the future the "controlling" machine will exercise political power over the world. Such reasoning appears to me frivolous. Even the most perfect machine will never be able to replace the creative effort and responsibility of man in any decision on a public matter, i.e., the legal regulation of social relations. There should be no illusions on that score.

The wealth of cybernetic possibilities will be realized in the sphere of public law only if account is taken of the laws of Marxist-Leninist sociology. This requires the study of the qualitative peculiarity of the social processes. Cybernetic machines will take over the most labor-consuming mechanical operations, freeing civil servants and law specialists to carry on higher forms of creative activity. The more labor functions are transferred to machines, the more the human in the human being will flourish, to use Karl Marx's expression. ${ }^{1}$ A cybernetic machine, especially in a socialist society, is no competitor of man, but an excellent instrument of his will-a reliable helper who multiplies the transforming power of his mind.

We must bear in mind that without the participation of specialists in the law, not even a highly-qualified cybernetics expert can apply the means and methods of cybernetics in the juridical sciences. The intricate problems of cybernetics in the sphere of public law can be solved only through the cooperation of engineers,

- Doctor of Legal Science, Leningrad 196r. Professor of Law und Head, Department of the Theory and History of State and Law, Leningrad University.

I KarL Marx, Das Kapitar 873-74 (6th ed. Berlin, 1957). 
mathematicians, psychologists, economists, and representatives of other sciences with theoretical and practical workers in the field of jurisprudence: Among these problems are reference and information service in the sphere of law, some aspects of legislation and codification, ${ }^{2}$ generalization of judicial practice, interpretation and application of legal norms, regular analysis of crime and convictions, the study of the causes of crime and the effectiveness of measures for wiping out crime, examinations by experts in criminalistics, and so on.

\section{Legal Reference and Information Services}

Let us take, for instance, the organization of a legal reference and information service. In seeking a solution for many theoretical and practical problems we find it necessary to familiarize ourselves with the results of all earlier investigations related to the problem in which we are interested, as well as all legislation and other legal materials which have a bearing on the problem. Already in the very early stages of work on a legal problem one begins to think about where the needed information can be found. When dealing with many problems of legislation, codification, interpretation, and application of the law, a quick and accurate orientation in the most diverse and rather broad sphere of legislation is required.

Legal rules, theoretical publications, and other legal materials evidently will increase in number. Hence, practitioners and theoreticians alike will have to spend more time searching for the needed legal information, leaving very little time for creative work. We therefore have to make use of the incomparably more effective means of finding, transmitting, and processing information now developed on the basis of the achievements of cybernetics.

The organization of a machine reference and information service in the sphere of law has a number of indisputable advantages. A special cybernetic system is capable of storing a large volume of information. It can quickly furnish any part of the stored information required, systematize such materials logically, and furnish legal information of the most diverse kinds, such as by country, historical periods, branch of the law, subject and method of legal regulation, and so on. Furthermore, what is especially important, a special cybernetic system can supply any desired combination of these materials.

\section{Legislation and Codification}

Take another problem of public law: legislation and codification. In the Soviet Union, millions of private citizens are enlisted to take part in the legislative process. At the stage of discussing draft laws, Soviet people express a vast number of concrete proposals, observations, and desires; and this participation by the whole nation in the discussion of bills makes for better Soviet laws. Not only in the process of national discussion of draft laws, but also in their daily public activity-especially

${ }^{2}$ As herein used, codification refers primarily-but not exclusively-to the compilation and consolidation of statutes and statutory instruments. 
during election campaigns-Soviet people advance valuable ideas for legislation, as well as other proposals on questions of law.

The need of properly and accurately expressing in Soviet law the common will of the whole people, of reflecting the matured and maturing requirements of progressive social development comprehensively and most expediently, gives rise to certain difficulties. All these difficulties will be eliminated by the use of the latest cybernetic equipment. With the aid of this equipment, full account can be taken of the suggestions made. A preliminary classification of the discussion materials can be undertaken in very brief time; and the machine's memory will ensure the orderly storage of the legislative recommendations which for one reason or another were not incorporated in the law as enacted but which might be utilized in future legislation. Cybernetic machines will also be of inestimable help in counting the votes cast in national referenda.

In the process of working on a draft of an important law, we must, as a rule, make a comparative analysis of the contents, the forms, the practical operation of legal rules regulating similar relations in the legislative systems of other countries or in other historical periods. A cybernetic machine can quickly select the data for such an analysis from the materials stored in its memory.

As we know, in the process of codification a lot of mental labor-in many cases "mechanical"-is expended, especially where the legislative materials involved are voluminous and fragmentary and have not been classified and systematized in a number of years. The special logical information machines can carry out various kinds of logical operations, such as finding the contradictions, inconsistencies, and duplications in existing legislation; and thereby not only lighten the codifier's burden, but also make for better codification.

No less effective is the application of the means and methods of cybernetics in generalizing judicial practice, i.e., searching for the most often repeated judicial errors; to bring out statistical indices for different offenses and their objects; to study the causes of crime and the effectiveness of measures for eradicating crime; to make various kinds of criminalistic examinations, and so on.

\section{Law Teaching}

We shall now deal with the use of cybernetic programming for law teaching. Regular strengthening of socialist law and ensuring exemplary law and order in the Soviet Union requires the training of highly qualified specialists in state administration and in jurisprudence. And while the Soviet universities cope with this problem quite successfully, this does not mean that we can not improve the system of legal education, in particular by the use of programmed teaching.

Research has permitted us to arrive at certain conclusions concerning the effectiveness of programmed teaching by means of cybernetics. Study becomes more vigorous; the role played by students working independently grows greater; and it takes less time to acquire the habit of independent thinking. The variety 
of forms in which the educational material is presented (printed, graphic, sound and TV screen) increases the volume of knowledge and improves its quality. Instruction takes on an individualized character, which takes into account the capability, bent, and speed with which each student masters the particular educational material. A greater demand is made upon the teachers, who have to know the material to perfection to be able to prepare for the most efficient programming, to understand more thoroughly the psychology of teaching, to analyze the reasons why some students find it difficult to assimilate the material and the ways to overcome the difficulties, and to change the tasks and methods of instruction by means of cybernetic-programming. The term of study is cut considerably, which in the final analysis means a saving of means spent by society on the system of education as a whole.

While instruction by cybernetic programming cannot completely take the place of the existing system of legal education, its use for conveying the needed legal information and knowledge to students is certainly advisable. Through the introduction of cybernetic programming into teaching we shall attain a higher degree of assimilation by students of such essential knowledge as classification of state organs; the structure, powers, and operation of state organs; the forms in which the law is created, their correlation, and legal force; the classification of legal standards, legal relationships, and juridical facts; the substance of legislation by branches of law or branches of the national economy; the rules for interpreting and applying the norms of the law; the operation of legal standards with respect to time, space, and section of the population; methods of legislative techniques used in current legislation and codification.

In addition to this, however, every lawyer must understand the essence of a particular state and its law, the class basis of a particular type of state and particular system of law, the particular role and social purpose of a particular state and law in various socioeconomic settings, and so on. And in respect of these the cybernetic programming method will not work. Hence, in my opinion, the system of legal education should be built on the principle of combining the usual methods of teaching with the gradual introduction of cybernetic-programming instruction, a combination which will yield more effective results.

In this connection, I must say that the American specialists' tendency toward teaching by programming in a utilitarian way is inadmissible as far as we are concerned because it materially limits the possibility of independent search, comparison of possible solutions, and decision. In brief, it restricts the creative effort of the students and the development of their capabilities. Study with the aid of machines will require far more general use of special cybernetic equipment as well as a far more "interesting," more "flexible" and more "elastic" program of study.

\section{Coding Problems}

The Legal Section of the Academy of Sciences Scientific Council on Cybernetics is now engaged in working out a law information machine language. There has 
to be worked out a system of attributes by which the legal material inserted into the machine is classified. To illustrate, the legislation of a country should be identified by a permanent code (special for each country) to be stored in fixed sections of the storage cell. This will make it possible to obtain quickly and simply all the information wanted about the legislation of the particular country. And, further, if every legal institution is identified by its permanent code situated in other fixed sections of the storage cell, by using this group of permanent codes it will be possible to obtain simply and quickly all information concerning a particular institution. Lastly, that will enable us to obtain all information wanted about a particular legal institution of the specific country in which we are interested.

The attributes by which the machine is to operate may vary greatly, and be applied in most diverse combinations. The system of attributes, for instance, may include the operation of legal norms in a particular part of the country; their applicability as regards different groups of the population, the respective organs, organizations, and officials; and the restriction of the application of the norms with respect to sex, age, family status, and so on.

Before the machine starts functioning, a specialist selects the information to be inserted, which in the process of its operation does not change the volume of information inserted in the machine (the feedback is actually a duplication of the information asked without elimination of the master information in the machine's memory). In contrast to this, all the other problems examined below relate to inserting in the machine specific selection criteria by the use of which the machine will not store every information but only such as is needed by the consumer.

The selection criteria (like the classification attributes for the preceding problem) may vary. The simplest criterion is the application of the legal norms with respect to time. This leads to the next special type of problem, the solution of which will make it possible to establish which of the laws or sections of statutes are no longer in force or still operate. In particular, where the law is codified the machine will be able to discover in the vast mass of legislative material the norms or sections which either have been repealed by later laws or whose period of operation has ended. This requires determining ( $I$ ) the system of attributes characterizing the term of operation of legal norms, (2) the method for extracting these attributes in a machine analysis of the legal text, and (3) the algorithm of the correlation of these attributes between themselves and the subsequent inference whether the norms are still in force.

Another selection criterion is checking the legislative material as to duplications. The machine can scan voluminous materials in brief time and discover not only nominal duplications but also duplications in essence (even where the verbal formulations of the law differ to a certain extent). Thus, in the course of drafting a statute, it would be advisable in many cases to find out with the aid of the machine whether the draft contains any provisions which fully or substantially duplicate already existing legislation. The machine, of course, would merely indicate the 
duplication, and it would be up to the legislative body to decide which of the redundant provisions should be approved because of their special significance and which should be deleted from the draft. The special problem in such cases is to work out the coding of the materials, i.e., to determine specific ways of labeling the components of the legal texts. The use of such labels will permit supplying the legal information in such a manner that the machine will be able to reveal the identical parts of legal texts.

The next selection criteria consist in making sure that there is nothing contradictory in the material to be inserted in the machine. A good illustration is the mechanization of graphological examinations needed for judicial purposes. For such expert examination, at first one part of the text is inserted in the machine. With the aid of the reading device, this is analyzed in conformity with the set program; and the machine's memory retains the numerical characteristics of the graphic peculiarities of the text (the handwriting). The subsequent insertion of the other parts of the same text makes it possible for the machine to reveal whether the numerical characteristics are the same in all the parts, or whether some sections of the text possess other numerical characteristics and hence are written by a different hand. In cases of this kind the problem, in the main, boils down to setting up a system of characteristics a deviation from which could with sufficient certainty be qualified as an inner contradiction of the material.

\section{Conclusion and Outlook}

Delinquency cannot be combated or prevented without keeping a record of the different forms of offenses and their cause. In many cases so many factors are involved that they cannot be encompassed without the use of electronic computers. Cybernetics can be used in the examination of handwritings and in forensic ballistics. Articles of the most diverse kind are objects of criminalistic examination. Many of them require a method of their own, and diversified apparatus. Here we face many independent problems in the solution of which the methods of applying cybernetics will be far from alike. Cybernetic methods may substantially influence the theory of criminalistic identification, a theory which embraces the general aspects of many spheres of criminalistics and is of great importance for expert testimony. The problems of using cybernetics for the objectification of criminalistic investigations of material evidence are currently being studied. .

Some results of research in cybernetics have already been realized in practice. For instance, the methodological problems have been worked out in the main; and experimental attempts to organize a legal reference and information service in the field of law have been successful. In response to inquiry, the machine gave out every kind of information on existing legislation stored in its memory. Criminal offenses, in particular offenses against socialist property, have been programmed. a case (in particular to determine damages to be assessed to each individual deElectronic computers are used also to solve separate problems arising in the trial of 
fendant where a number of defendants are charged with causing damage to public property). An automatic dactyloscoping machine which can instantly find the needed fingerprint card has been developed.

Some three years ago the Soviet government adopted a comprehensive program for mechanizing accounting, planning and designing, and engineering and technical services. When the program is carried out, many people will be released for other work. There will be an immense saving in time and money, and the work of managing the planned and progressive development of our society (and of services connected therewith) will be facilitated considerably. 